\title{
Letter
}

\section{Clinical Impact of Dysglycemia in Patients with an Acute Myocardial Infarction (Diabetes Metab J 2021;45:270-4)}

\author{
Bo-Yeon Kim
}

Division of Endocrinology and Metabolism, Department of Internal Medicine, Soonchunhyang University Bucheon Hospital, Soonchunhyang University College of Medicine, Bucheon, Korea

In patients with acute myocardial infarction (AMI), blood glucose on admission is affected by metabolic stress caused by acute ischemia, and increases in-hospital mortality regardless of diabetes [1,2]. In particular, the incidence of congestive heart failure and cardiogenic shock is increased in patients without diabetes [3]. In a study conducted on patients in the Korea Acute Myocardial Infarction Registry from 2005 to 2008, admission glucose in patients with AMI correlated significantly with in-hospital and 1-year mortality [1].

In the article entitled "Clinical impact of dysglycemia in patients with an acute myocardial infarction," Chung et al. [4] sought to determine the impact of dysglycemia on myocardial injury, cardiac function, and 30-day mortality in AMI patients who underwent percutaneous coronary intervention. This study has several strengths compared to previous studies. First, laboratory parameters, including serum $\mathrm{N}$-terminal pro-Btype natriuretic peptide (NT-proBNP), peak troponin I and aspartate aminotransferase (AST) level at admission as a marker of myocardial injury, white blood cell (WBC) count, and representative echocardiographic parameters were measured. Second, diabetes mellitus was defined based on patientreported history, medical records, a glycosylated hemoglobin value of $\geq 6.5 \%$, or an oral glucose tolerance test during the admission period. Therefore, in this study, diabetes and non-diabetes were distinguished relatively accurately. Third, initial plasma glucose level on admission was divided into five groups. In addition, the relationship between laboratory and echocardiographic parameters and mortality rate according to admission glucose level are shown in diabetics and non-diabetics, respectively.

Despite its strengths, there are several issues not addressed in this study. First, severe hyperglycemia (Group 5) among AMI patients was associated with greater 30-day mortality in the nondiabetic group than the diabetic group. Also, troponin I and AST levels were higher among nondiabetics. These findings suggest that hyperglycemia may be at least in part a reflection of greater disease severity. Because glucose level before AMI is usually higher in diabetics, higher admission glucose might induce oxidative stress [5]. This may explain why hyperglycemia-associated risk is highest in patients without diabetes. Another explanation is paradoxical resistance of diabetic hearts to ischemic episodes. Although controversy exists as to whether diabetic hearts are more or less sensitive to ischemic injury, in vitro studies have consistently demonstrated that diabetic hearts are less susceptible to injury after an episode of ischemia [6]. In another study, diabetic patients with an admission glucose of 9 to $10 \mathrm{mmol} / \mathrm{L}$ had the lowest mortality, whereas lower glucose improved survival in nondiabetic patients [5]. I thus suggest that optimal glucose level on admission may vary between diabetic and nondiabetic patients with AMI. In addition, as the authors mentioned, there was a limited number of patients in Group $1(<80 \mathrm{mg} / \mathrm{dL}, n=5)$, so it was
Corresponding author: Bo-Yeon Kim (iD https://orcid.org/0000-0002-3658-2351 Division of Endocrinology and Metabolism, Department of Internal Medicine, Soonchunhyang University Bucheon Hospital, Soonchunhyang University College of Medicine, 170 Jomaru-ro, Wonmi-gu, Bucheon 14584, Korea

E-mail: byby815@schmc.ac.kr
This is an Open Access article distributed under the terms of the Creative Commons Attribution Non-Commercial License (https://creativecommons.org/licenses/by-nc/4.0/) which permits unrestricted non-commercial use, distribution, and reproduction in any medium, provided the original work is properly cited. 
difficult to accurately assess the relationship between hypoglycemia and myocardial injury or dysfunction. In a previous study, hypoglycemia in AMI patients with or without type 2 diabetes mellitus was an important factor related to 30-day mortality [7]. In this study, patients with admission hypoglycemia had the highest NT-proBNP level and E/E' ratio and lowest WBC count. This is an unexpected result that might be clarified in a larger study population.

In conclusion, dysglycemia, especially hyperglycemia, appears to be associated with myocardial injury, and could be another parameter for predicting short-term mortality in patients with AMI. Additional prospective studies should be conducted to elucidate the association between hyperglycemia, hypoglycemia and mortality in patients with AMI.

\section{CONFLICTS OF INTEREST}

No potential conflict of interest relevant to this article was reported.

\section{REFERENCES}

1. Kim EJ, Park OJ, Jeong MH, Ahn YK, Kim JH, Kim YJ, et al.
Admission glucose is a useful prognostic factor in patients with acute myocardial infarction. Korean J Med 2010;79:23-31.

2. Kim CM, Yu KD, Moon KW, Paek SH, Park YG, Rho TH, et al. Glucose-insulin-potassium as an adjunctive therapy in acute myocardial infarction. Korean Circ J 2005;35:779-86.

3. Capes SE, Hunt D, Malmberg K, Gerstein HC. Stress hyperglycaemia and increased risk of death after myocardial infarction in patients with and without diabetes: a systematic overview. Lancet 2000;355:773-8.

4. Chung JW, Park YS, Seo JE, Son Y, Oh CW, Lee CH, et al. Clinical impact of dysglycemia in patients with an acute myocardial infarction. Diabetes Metab J 2021;45:270-4.

5. Monnier L, Mas E, Ginet C, Michel F, Villon L, Cristol JP, et al. Activation of oxidative stress by acute glucose fluctuations compared with sustained chronic hyperglycemia in patients with type 2 diabetes. JAMA 2006;295:1681-7.

6. Desouza C, Salazar H, Cheong B, Murgo J, Fonseca V. Association of hypoglycemia and cardiac ischemia: a study based on continuous monitoring. Diabetes Care 2003;26:1485-9.

7. Ishihara M, Kojima S, Sakamoto T, Kimura K, Kosuge M, Asada $\mathrm{Y}$, et al. Comparison of blood glucose values on admission for acute myocardial infarction in patients with versus without diabetes mellitus. Am J Cardiol 2009;104:769-74. 